\title{
La cabecera como signo de identidad del producto periódico: una aproximación teórico-práctica a los rótulos de la prensa diaria española en 2013
}

\author{
Headboard as a sign of identity \\ of the product newspaper: \\ a theoretical and practical approach \\ to callouts of the Spanish daily press in 2013
}

Laura González Diez

Profesora Agregada de Diseño Periodístico (Universidad CEU San Pablo)

Pedro Pérez Cuadrado

Profesor Titular de Diseño Periodístico (Universidad Rey Juan Carlos de Madrid)

Fecha de recepción: 9 de diciembre de 2013

Fecha de revisión: 19 de diciembre de 2013

Para citar este artículo: González Díez, L. y Pérez Cuadrado, P. (2014): La cabecera como signo de identidad del producto periódico: una aproximación teórico-práctica a los rótulos de la prensa diaria española en 2013, Icono 14, volumen (12), pp. 31-62. doi: 10.7195/ri14.v12i1.637 


\section{Resumen}

El presente artículo de investigación plantea, de un lado, una revisión teórica sobre uno de los elementos básicos de la identidad visual de la prensa diaria: la cabecera, elemento que permite al periódico adoptar una imagen editorial propia y diferencial frente a sus competidores debido a su valor corporativo y cuya aproximación teórica no ha sido abordada con claridad por parte de los principales expertos del diseño periodístico. De otro lado, el artículo da a conocer los resultados de un trabajo de campo centrado en el estudio de las cabeceras de las ediciones impresas de los diarios españoles y que analiza el aspecto formal gráfico y tipográfico de este elemento fundamental, para lo que se ha trabajado con una muestra integrada por más de un centenar de periódicos. Todo ello nos ha permitido concluir que la cabecera tipo de los periódicos diarios impresos españoles es un rótulo compuesto con tipografía de palo seco, en color negro, en positivo, de caja alta y baja, centrado al ancho de la mancha, volado y con un filete que subraya el conjunto.

Palabras clave: Cabecera - Tipografía - Diseño periodístico - Identidad visual

\section{Abstract}

This research article raises, on one hand, a theoretical review about one of the basic elements of the visual identity of the daily press: the headboard, element that allows the newspaper to show a differential and own editorial image over its competitors due to its corporate value and whose theoretical approach has not been clearly addressed by leading experts of the newspaper design. On the other hand, the article gives the results of field work focused on the study of the headboards of the printed editions of Spanish newspapers and which analyzes the graphic and typographic formal aspect of this essential element, for which we have worked with an integrated sample composed by more than one hundred newspapers. All this allowed us to conclude that the header type of printed Spanish daily newspapers is a compound sign composed by a sans serif typography, in black colour, in positive, in upper and lowercase, focused to the width of the stain, flown and a line that underlines the whole set.

Key Words: Headboard - Typography - Newspaper design - Visual identity 


\section{Introducción}

Uno de los elementos básicos de la identidad visual de la prensa diaria lo constituye la cabecera, ya que permite al periódico adoptar una imagen editorial propia y diferencial frente a sus competidores debido al valor corporativo que encierra.

A pesar de ser uno de los elementos esenciales de cualquier publicación periódica, ya sea en su versión impresa o digital, hasta el momento no ha sido abordado con claridad por los teóricos del diseño periodístico. Por tanto, nuestro primer objetivo será el de realizar una revisión teórica de cuanto se ha publicado hasta el momento sobre este elemento básico de la portada de los diarios y ofrecer una visión propia sobre las características de las cabeceras, los elementos que la integran o su clasificación.

El segundo objetivo es el de ofrecer datos relevantes sobre el aspecto gráfico y tipográfico que las cabeceras de los diarios españoles presentan en la actualidad, para lo que se ha realizado un trabajo de campo sobre una muestra de 115 diarios impresos a partir de una ficha metodológica diseñada para tal efecto.

Como punto de partida nos situamos en la definición recogida por la vigésimo segunda edición del Diccionario de la Lengua Española, que entiende por cabecera, en la acepción número 13, "el nombre de un periódico registrado como propiedad de una persona o entidad mercantil, que suele ir en la primera página". Sin embargo, José Manuel de Pablos (2003: 15) afirma que esta definición contiene errores. Uno de ellos, asegura el autor, es que entonces el nombre de una publicación clandestina no sería cabecera, pues dice la Real Academia que tiene que tratarse de un periódico registrado. Otro error sería el del registro como propiedad de una persona o entidad mercantil, lo que supondría que no podrían tener cabeceras las revistas del obispado, las publicaciones de partidos políticos, sindicatos o asociaciones, ya que no están a nombre de una persona ni son entidades mercantiles. El mismo autor define el término cabecera como "título o nombre de una publicación, que se encuentra destacada, siempre y no sólo a veces, en su primera página". 
Uno de los más antiguos tratados sobre Periodismo, el de Rafael Mainar, ya dedicaba un amplio espacio a la idea de la cabecera en los periódicos, a la que tildaba de "sello personalísimo (...) que no debe variarse bajo ningún concepto" (Mainar, 1906: 62). Así de rotundo se mostraba el autor, quien además matizaba: "Sus proporciones en relación con el alto de la página, excepto los blancos marginales, no puede exceder, so pena de resultar fea y cabezuda la plana, de una décima parte de ésta. Aun dentro de esta proporción, es preferible que peque por pequeña que por grande, siempre que resulte perfectamente visible a alguna distancia y, sobre todo, de un tipo muy negro, claro, sin adornos, de palo seco". Consideramos que se trata de una definición muy precisa, probablemente la más clara de todas las aportadas por los teóricos del Periodismo y del diseño de publicaciones.

Uno de los autores más prolíficos al hablar de cabeceras es Edmund Arnold, quien la define como "rótulo y marca de fábrica de un periódico", pero también emplea otros sinónimos, fundamentalmente el de bandera (flag en inglés) porque dice que "al igual que una bandera inspira orgullo y respeto, la cabecera de un periódico debe ser fuente de orgullo para los que trabajan en él y de respeto para sus lectores" (1965: 71).

Este autor (1984: 91) utiliza también para referirse a la cabecera el nombre de nameplate, y la enmarca dentro de lo que denomina "constantes", en referencia a aquellos elementos del periódico que no son reemplazados con frecuencia, sino que poseen una larga vigencia, de los cuales señala que es la más importante, “es una marca registrada, y es más como un escudo de armas que un simple implemento comercial. Mirar la placa con el nombre de un gran periódico es resumir la historia, leyenda y espíritu de una institución perdurable".

Por su parte, Mario R. García se decanta por el sinónimo "cabezal" y lo considera "el elemento tipográfico más constante del periódico (...) y vínculo de identificación entre el periódico y el lector, que debe sugerir a la primera mirada su personalidad, a la vez que ofrece una visión de las características de su entorno" (García, 1984: 100).

ICONO14 | Año 2014 Volumen 12 NN$^{\circ} 1$ | ISSN: 1697-8293 | DOI: ri14.v12i1.637 
De hecho, la cabecera es un elemento de cualquier tipo de publicación que contribuye a reforzar la identidad del mismo; a esto añade González Solas (2002: 4849) que "la identidad del periódico o revista está constituida por ciertos elementos constantes, tales como la cabecera (...)".

Fernando Lallana denomina también alas cabeceras manchetas y logotipos (Lallana, 2000: 143). Esta acepción de mancheta es compartida por los profesores Armentia Vizuete y Canga Larequi, y también es de uso frecuente entre los profesionales de los medios durante la segunda mitad del siglo pasado. Sin embargo, otros autores utilizan este término para referirse al staff de la publicación.

Probablemente, el origen de la confusión provenga del libro Concepción y confección de un periódico, de A. Sutton, quien textualmente dice "muchos periódicos incluyen pequeñas masas de tipo o ilustraciones a cada lado -a veces a uno solo de los lados- de la cabecera para añadir datos sobre el periódico o las noticias que contienen. En otras épocas se utilizaban únicamente con fines decorativos. Se llaman manchetas" (Sutton, 1963: 308). Si tenemos en cuenta que muchas de estas manchetas incluían datos sobre el personal del diario parece lógico, en ambos casos, que por extensión sugirieron el equívoco para asimilar ambos términos.

No obstante, Sutton define la cabecera como "designación general del periódico, que contiene el nombre de la publicación y normalmente está impreso en una plancha de metal duradero. La cabecera -dice- identifica al periódico y da algunos datos significativos acerca de la publicación" (Sutton, 1963: 308).

En cuanto a las acepciones "rótulo" y "título" hay que señalar que tienen un significado similar. Así lo demuestra el Diccionario Anaya de la Lengua, que define "rótulo" como el "título de un escrito o de una de sus partes" (VV. AA., 1991: 854). Con todo, "cabecera" es la palabra que mejor se adecúa a este elemento gráfico $\mathrm{y}$, además, es el término que se ha asentado en España para referirse al encabezado de la primera página en cualquier publicación.

El Diccionario de información, comunicación y periodismo ofrece una definición muy completa al decir que es el "conjunto logotípico que forma el dibujo o esque- 
ma gráfico que constituye el título de la publicación, que puede registrarse como marca comercial en la Propiedad Industrial (el título se registra en la Propiedad Intelectual)" (Martínez de Sousa, 1981: 47).

Finalmente, podemos concluir que la cabecera es la representación gráfica del nombre o marca registrada de la publicación que acostumbra a colocarse en la parte superior de la primera página, acompañada de la fecha, número, lema y elementos icónicos, si proceden, y cuya función es identificar la personalidad del diario.

\subsection{La cabecera como imagen de marca}

Las cabeceras de los periódicos superan el valor textual implícito y se acercan más a un logotipo que configura una imagen de marca del propio medio con un valor consolidado. Mario García (1984: 112) asegura que los lectores mantienen la misma "relación" con la cabecera del diario que leen habitualmente que con las marcas y nombres de productos que consumen a diario. El rótulo se convierte así en el elemento identificador el periódico. De hecho, Lallana (2000: 143) afirma que "una de las estrategias para crear identidad de marca consiste en la reiteración de la cabecera en aquellos productos que salen de sus rotativas". Este elemento identificador aparece tanto en "la publicidad del diario, como en todos sus suplemen-

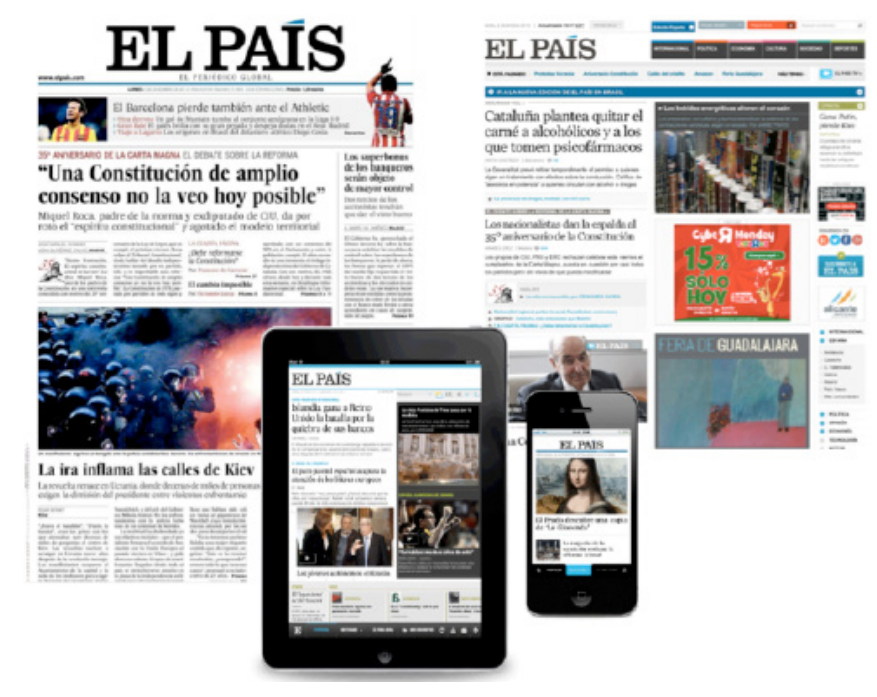
tos, coleccionables, libros 0 aquellos objetos de promoción incluidos en la compra del diario" $\mathrm{y}$, también, en las versiones digitales del periódico (web, tableta o móvil). En palabras de López del Ramo (2012: 2) "los ciberdiarios incorporan elementos heredados de la tradición impresa, que a

Figura 1. Cabecera de El País implementada en diferentes soportes 
veces se reconfiguran o adaptan al nuevo contexto. De entre ellos, la cabecera es el elemento gráfico que con más fuerza ha marcado una continuidad desde el periódico impreso y el digital".

Ya en 1906 Rafael Mainar (1906: 43) destacaba un detalle legal de propiedad industrial que "autorizaba para registrar como marca de comercio la cabecera de los periódicos y su nombre". No se registra el título como marca comercial, sino el rótulo del periódico que "ya nadie puede copiar ni siquiera imitar en la nación".

Arnold (1965: 71), cuando dice que la cabecera de un periódico es la "marca de fábrica" del mismo, insiste en que su elaboración debe implicar la misma estrategia que emplea una gran empresa para seleccionar el nombre de su marca y diseñar su logotipo. En este sentido, Rehe señalaba que "la cabecera del periódico debería ser parte integrante de una corporate identity completa" (1990: 59).

Por otro lado, Santesmases (1999: 388) asegura que dentro de una marca podemos distinguir el nombre y el logotipo. "El nombre -dice- es la parte de la marca que se pronuncia. Es la denominación de un producto específico de una empresa". De otra parte, el logotipo "es el grafismo empleado para distinguir una marca, un producto, una empresa o cualquier organización o conmemoración". Aunque, en general, el logotipo es un diseño elaborado que combina el nombre con símbolos y colores identificativos, muchas veces el logotipo incluye únicamente el nombre de la empresa o producto con una tipografía específica. En el caso de la cabecera esto no es posible, puesto que al nombre o logo en sí se le añaden siempre los datos de edición del diario, que son parte intrínseca del todo, $\mathrm{y}$, a menudo, van acompañados por elementos tipográficos no textuales (filetes, lutos, etc.) $\mathrm{y}$, a veces, símbolos de diversa índole. Por su parte, Martínez-Fresneda (2007: 105) considera que su diseño "debe ser único y exponer de manera clara la identidad del periódico" y añade, "debe reflejar el concepto del periódico, su tradición y sus valores y también la clase de lector al que se quiere interesar".

Aunque la analogía cabecera/logotipo pudiera quedar patente a la vista del parecido papel que desempeñan $\mathrm{y}$, aunque la cabecera es vista como el principal elemento identificador del periódico, no se la considera protagonista principal de 
la imagen de marca del producto. Ninguno de los autores antes citados se refieren a la cabecera como imagen de marca del producto periódico en sí y no se estudian los valores y atributos de marca que se esconden tras su diseño, lo que Martín García (2004: 41) llama "asociaciones de la marca", conjunto de vocaciones que suscita en el público. Dicho de otra manera, no se refieren a cómo es percibida por el consumidor, a las emociones que la cabecera provoca en él. No analizan de qué manera interactúa la cabecera con los consumidores.

De cualquier forma, el logotipo de cualquier marca comercial y la cabecera de un diario tienen características similares. Ambos deben ser: legibles, distintivos, estéticamente atractivos, cortos y fácilmente pronunciables. Deben reproducirse siempre del mismo modo, sin mermar nunca su legibilidad. Deben ser reflejo de la personalidad del periódico. Deben añadir valor al producto y diferenciarlo de la competencia. Y, por último, deben dar información sobre la calidad, fiabilidad y valor del mismo.

\subsection{La cabecera como imagen de marca}

El diseño de la cabecera responde a la combinación de diversos elementos y acepta numerosas formulaciones. Si bien alguno de ellos es imprescindible (título de la publicación, número o fecha), también hay recursos que pueden no ser empleados (elementos icónicos, por ejemplo). El diseño de la cabecera dependerá de las exigencias del diario, pero también del gusto y creatividad del diseñador.

Para Rehe (1990: 97) "la cabecera no se debería recargar con demasiados elementos. Lo mejor es rodearla con suficiente espacio en blanco, lo cual le confiere autoridad y dignidad". Arnold (1965: 73-79) distingue, como posibles elementos de la cabecera, los siguientes:

- Nombre o título: componente imprescindible del rótulo. Su extensión determinará el diseño de éste.

- Lema: figura que suele resaltar alguna virtud de la publicación: Por ejemplo, en El País, "El periódico global en español". 
- Orejas: elemento que se coloca a uno o ambos lados de la cabecera. Su contenido es variable, pero puede incluir datos registrales o de edición del ejemplar (número de la publicación, fecha, precio...), informaciones desarrolladas en el interior del diario o, simplemente, espacios vacíos.

- Elementos icónicos (símbolos, emblemas, escudos, etcétera): No todos los periódicos incluyen este elemento. Su uso es más común en los diarios locales o regionales, generalmente para facilitar la identificación de la publicación con una determinada zona geográfica.

- Ilustraciones: Arnold incluye en este apartado las imágenes del edificio donde se confecciona el periódico o un edificio distintivo o identificativo de la zona donde la publicación va a ser vendida. En la actualidad, no es habitual encontrar ilustraciones insertadas en la cabecera.

- Mención aparte merece la inclusión de publicidad. No es habitual encontrar anuncios en la zona que por naturaleza suele ocupar el rótulo de un diario, pero en ocasiones así sucede. Esto se debe, en la práctica totalidad de los casos, a la importancia económica de la publicidad y a que la portada es la página preferida por los anunciantes para colocar sus reclamos, puesto que es lo primero que verá el lector. Dentro de la primera página, la zona donde se coloca la cabecera resulta especialmente atractiva, dado que es un primer centro de impacto visual. Las publicaciones gratuitas, que viven a expensas de la publicidad, sacrifican a menudo el espacio natural del rótulo para colocar anuncios en su lugar. En cambio, los periódicos tradicionales de información general no suelen someterse a esta práctica.
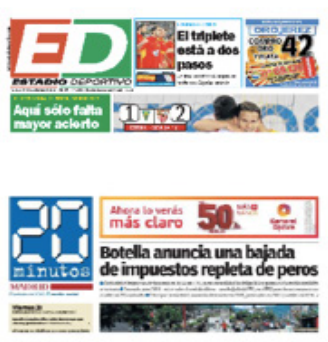
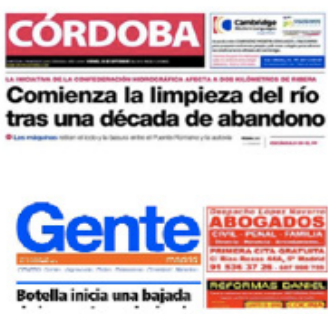
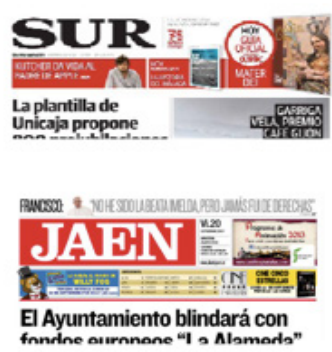

Figura 2. Diferentes ejemplos de incorporación de publicidad en la cabecera 
Consideramos que la enumeración que Arnold menciona es incompleta a día de hoy. Habría que añadir, como mínimo:

- Filetes y orlas: se pueden definir como el "recurso tipográfico consistente en rayas o líneas de diferente grosor y estilo utilizada para enfatizar los textos o informaciones de una página" (González Díez y Pérez Cuadrado, 2001: 211). En el caso de la cabecera, el uso de un filete sirve, por una parte, para delimitar el espacio que ocupa $\mathrm{y}$, por otra, para resaltarla sobre el resto del contenido de la portada.

- Blancos: parte no impresa de la página. Arnold apunta, al mencionar el espacio reservado para las orejas, que "esos espacios serían mucho más eficaces si se dejasen en blanco, un cielo amplio en que la bandera ondease orgullosamente" (Arnold, 1965: 77).

- El color: es un recurso que, tras la revolución de los sistemas de impresión, se ha ido incorporando a las portadas de los diarios de forma progresiva. La cabecera, al liberarse de la impresión bicolor, ha ganado fuerza y personalidad.

\subsection{Características de la cabecera}

Podemos considerar cuatro características básicas que deben ser aplicables a cualquier cabecera: debe ser legible, identificativa de la personalidad del periódico, atractiva y distintiva.

Para lograr estos objetivos, lo primero que debe hacer el diseñador es elegir la familia tipográfica adecuada para el nombre de la publicación. Cada tipografía conlleva ciertos valores subjetivos que el lector percibe casi sin darse cuenta. Por ello, es importante seleccionar aquella tipografía que mejor se identifique con el diario.

También, es imprescindible que el rótulo sea legible y de fácil reproducción. Al ser el elemento identificador del diario, la cabecera aparecerá impre- 
sa no sólo en la publicidad del mismo, sino también en cualquier suplemento relacionado con el periódico. Lallana aseguraba que la cabecera, al ser el logotipo del diario, debe ser diseñada teniendo en cuenta su posterior reducción o ampliación. Por ello, el rótulo debe ser legible no sólo en la portada del diario, sino también cuando aparezca impreso en cualquier parte con un tamaño diferente (Lallana, 2000: 143). Esta aclaración cobra más fuerza en la actualidad ya que la cabecera también se reproduce, de forma reducida, en las versiones digitales de los diarios, tanto en el teléfono móvil, como en las tabletas o en la web.

Si exceptuamos las indicaciones de Mainar referentes a las medidas de la cabecera, no hay ningún acuerdo tácito sobre el tema. Ni tampoco sobre la situación precisa de ésta. El rótulo, al ser uno de los elementos fijos en el diseño de cualquier publicación, ocupa siempre el mismo lugar en la portada. En cambio, sí puede alterarse el orden de la primera página si se producen acontecimientos de especial relevancia que merezcan un espacio destacado en la portada. Es el caso de grandes catástrofes, noticias de índole política 0 deportivas con gran relevancia. Además, en estos casos también puede romperse la jerarquía en la primera plana, apareciendo titulares con un cuerpo muy superior al habitual y casi siempre a toda página, alcanzando éstos el protagonismo de la cabecera.

En Tipografía y diagramado para periódicos, Arnold hace una curiosa observación: "el rótulo o bandera del periódico, si es flotante o corto, puede ser un factor para colocar los dos primeros elementos informativos en lo alto de la página. Estas banderas flotantes están ganando cada día mayor popularidad, y hay un buen motivo para ello. Una bandera a ocho columnas es como la tapa de una olla, en cuanto a que se queda en una posición y poco tiene que ver con el guiso que se hierve en la vasija. Una bandera corta se convierte en parte integral del guiso. La bandera puede ondear en cualquier sitio del tercio superior de la página sin dejar de cumplir su función de identificar el periódico" (Arnold, 1965: 124 y 125). 

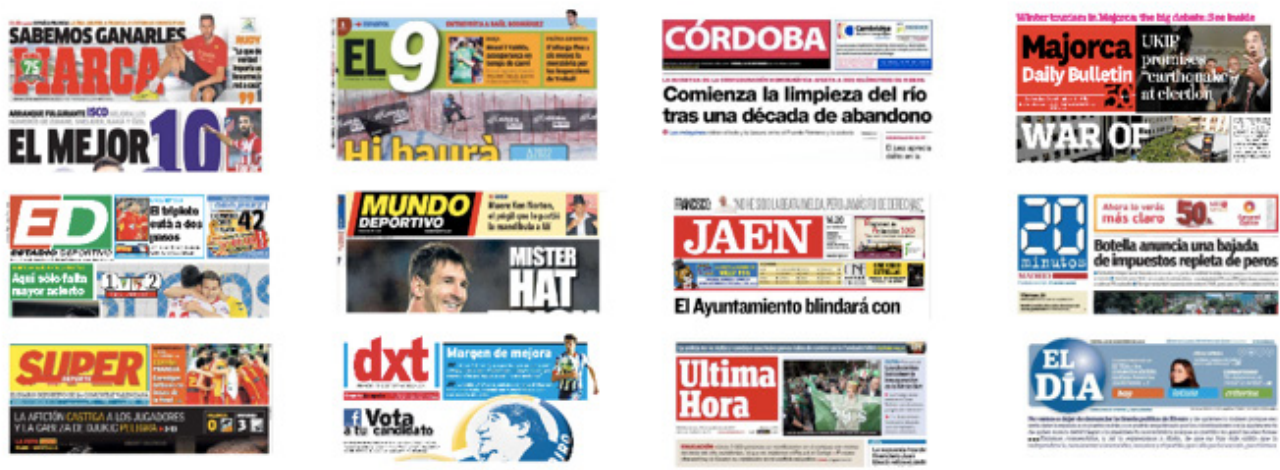

Figura 3. Diferentes ejemplos de cabeceras en pastilla

Por su parte, Mario García afirma que "las cabeceras cumplen mejor sus funciones cuando se colocan en la parte superior de las páginas, ocupando todo el ancho (...) pero a veces se utilizan cabeceras volantes para destacar una noticia de última hora que se coloca en la parte más alta de la página. La cabecera volante no debe colocarse nunca a una distancia mayor de 12 ó 13 centímetros contando desde el borde superior de la página (García, 1984: 112).

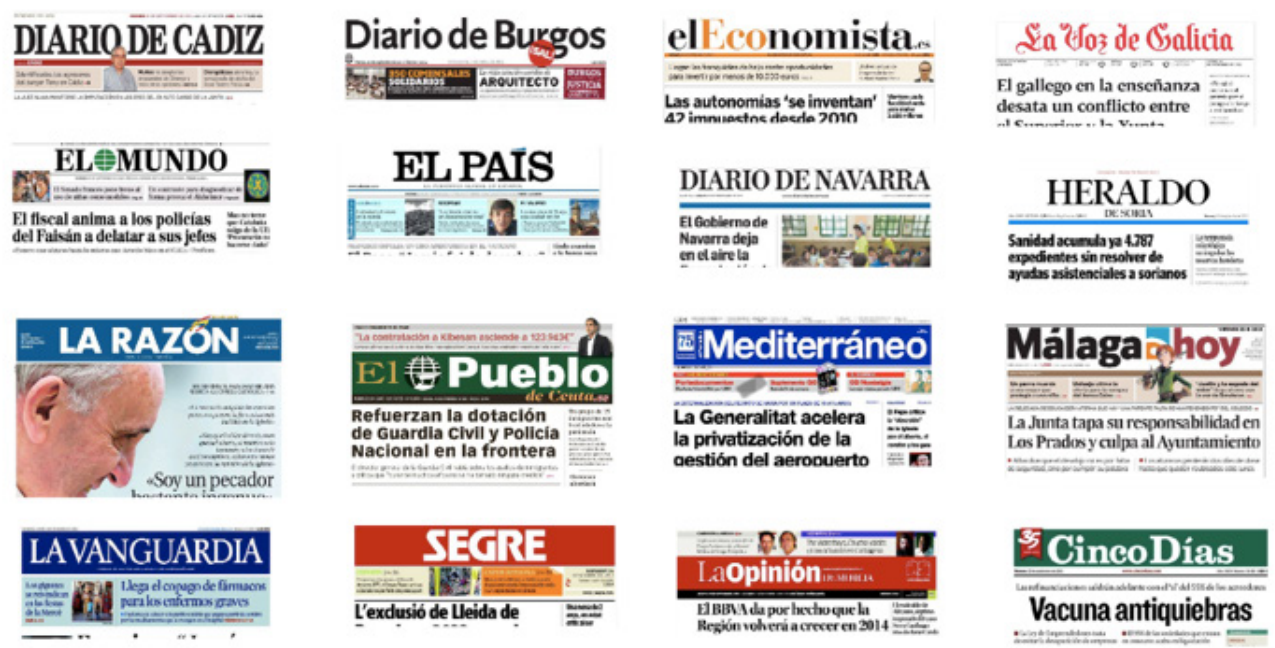

Figura 4. Diferentes ejemplos de cabeceras al ancho de la mancha

ICONO14 | Año 2014 Volumen 12 NN $^{\circ}$ | ISSN: 1697-8293 | DOI: ri14.v12i1.637 


\subsection{Clasificación}

Respecto al ordenamiento de las cabeceras no hay un patrón unánime en prensa diaria más allá de una estructuración basada en el empleo de la tipografía (con/sin serif), del color, del estilo o de su posicionamiento. Muy pocos autores se han atrevido con una clasificación mínimamente consensuada. De hecho, tan solo el profesor Lallana ofreció una división en tres categorías: clásicas, modernas y de transición (Lallana, 2000: 133), que no tienen nada que ver con la tipografía utilizada en las mismas.

Para Lallana una cabecera clásica es aquella que presenta una mancha ligera, negro sobre blanco, con estilo en redonda, mayúsculas, con integración de dibujos por línea donde fundamentalmente aparecerían góticas y romanas. Las modernas, por otro lado, ofrecerían el empleo del color en mayor grado, soluciones icónicas integradas en la tipografía, negativos y letras de palo seco. Por último, considera de transición a las cabeceras a medias entre los dos estilos anteriores, con un eje central de simetría.

“Si bien es cierto - comenta Lallana- que cada tipología responde a un momento histórico concreto, hoy día se publican diarios con cabeceras de los tres grupos indistintamente. Los rasgos de los rótulos actuales responden tanto al diseño más en boga como a la necesidad de identificar el diario con los contenidos. Por ejemplo, un diario de información general que defienda los valores tradicionales puede elegir una tipografía gótica para su cabecera, aunque la tendencia actual se incline más por los tipos sin remate, imitando al USA Today" (Lallana, 2000: 133).

Por su parte, Martínez-Fresneda (2007: 105) y Canga Larequi (1994: 62) clasifican las cabeceras según su posición dentro de la página y diferencian entre cabeceras a toda página -situadas en la parte superior o centradas- y cabeceras en pastilla, esto es, a un lado de la página.

DOI: ri14.v12i1.637 | ISSN: 1697-8293 | Año 2014 Volumen 12 Nº 1 | ICONO14 


\section{Trabajo de campo: muestra y métodos}

La investigación planteada para este artículo ha consistido en un análisis pormenorizado de la totalidad de las cabeceras de los periódicos diarios españoles, es decir, la muestra la compone el universo de los diarios impresos publicados en España. A fecha 20 de septiembre de 2013 en España se publicaban 127 diarios. Para el estudio se han tenido en cuenta no sólo las empresas que figuran en los datos de la Oficina para la Justificación de la Difusión (0JD) y el Estudio General de Medios (EGM) sino todos aquellos que mantienen una publicación constante en los últimos diez años. Pero no se han contabilizado aquellos que repiten cabecera idéntica en diferentes provincias e incluso diferentes comunidades autónomas, caso de algunos diarios del Grupo Correo como La Verdad (Murcia y Comunidad Valenciana) o el propio El Correo (La Rioja y País Vasco); o como las distintas ediciones de Faro en Ceuta y Melilla o los diferentes La Tribuna en Castilla-La Mancha. La muestra resultante entonces ha estado integrada por un total de 115 diarios, donde se incluyen tanto los periódicos de información general, como los económicos, deportivos y gratuitos, aunque estas tres últimas categorías se hayan considerado aparte, como es lógico, para el análisis final. Esto ha supuesto abarcar la totalidad del espectro de los diarios impresos en España y ha permitido obtener una importante cantidad de datos representativos sobre las cabeceras.

El punto de partida fue el diseño de una ficha metodológica que incluía un código de análisis basado en 52 variables (ver anexo), para operar en dos fases diferenciadas. Las primeras cincuenta variables insisten en elementos formales y de diseño que aportan fundamentalmente datos cuantitativos y dibujan un modelo de cabecera, que aparece en algunos modelos de diarios, un tanto rígido (como todos los resultados numéricos) y que no podemos asegurar que se identifique plenamente con la mayoría de los grupos de prensa españoles.

En una segunda fase se procedió al cruce de los datos cuantitativos obtenidos con clasificaciones previas consensuadas de diferentes autores al respecto de la relación continente/contenido, con la intención de encontrar conclusiones válidas que permitieran fundamentar la investigación. 
Así, en este segundo proceso se volvió a considerar la totalidad de la muestra con dos nuevas variables. En la variable ${ }^{0} 51$ se trató de clasificar los modelos de diarios analizados con base en las propuestas de Casasús (1979, 1981 y 1991) cuando habla de hemerografía estructural y combina los análisis morfológico y de contenido. Casasús, que cita autores de referencia como Kayser, Moles, MacLuhan, Pasquali o Morin, y contempla dentro de la mecánica de la investigación las reglas de medición y cómputo (hemerometría), propone una clasificación de diario en su relación diseño/contenido donde habla de diarios informativo-interpretativos, de diarios de opinión, y de diarios popularessensacionalistas; y en un segundo plano (pero no por ello menos importante) de diarios 'híbridos' como mezcla de los anteriores.

En realidad se trataba de averiguar en qué medida "una gran mayoría de los mensajes tratados por el análisis de contenido están formados -en palabras de Abraham Moles (Casasús, 1979: 52)- por la superposición de un mensaje semántico (denotativo: lo que se dice) y de un mensaje estético (connotativo: la manera en que se dice).

En la variable $n^{0} 52$ se trataba de adscribir los elementos de análisis de la muestra en función del tipo de portada donde se presentaban. Se pretendía comprobar si se daba una variable tipográfica o de otra índole en las cabeceras de los distintos modelos de primeras páginas.

No resultó fácil encontrar una tipología de portadas que permitiera la adscripción de una manera precisa y el análisis se hizo con la propuesta del profesor Martín Aguado (1981, 1986, 1987 y 1992) que también suscribe Jesús Canga (1994: 81) y que habla de portadas tipo escaparate, portadas de llamada y portadas mixtas. Para estos autores la portada escaparate es aquella que pretende ofrecer un resumen completo del contenido del periódico y, por consiguiente, la actualidad del día; mientras que la portada de llamada "soslaya el resumir la actualidad del día para centrar su atención y reclamar la del lector sobre un aspecto o noticia única" (Canga, 1994: 82). 
No está lejos esta propuesta de aquellas que otros autores (Evans, 1985 y Mario García, 1984 y 1989) denominan portada de señal y texto y portada póster, con las mismas características apuntadas.

\section{Resultados}

Como hemos adelantado, el primer resultado que podemos obtener tras la realización de nuestra investigación es que la cabecera tipo de los periódicos diarios impresos españoles es un rótulo compuesto con tipografía de palo seco, en color negro, en positivo, de caja alta y baja, centrado al ancho de la mancha, volado, con un filete que subraya el conjunto y que no lleva orejas.

Dado que este primer resultado no deja de ser una media cuantitativa que, sin ser falsa, no identificaría totalmente a la prensa española, a continuación presentamos de forma pormenorizada los resultados que ofrecen las variables morfológicas (las cincuenta primeras) y, con posterioridad, recogemos las variables interpretativas (las dos últimas). El cruce de ambas categorías nos ha permitido llegar a una serie de conclusiones que se expondrán a continuación.

\subsection{Variables morfológicas}

Las primeras variables del trabajo de campo nos han ofrecido unos resultados que hacen referencia, fundamentalmente, al tamaño, al uso tipográfico (familia, estilo...), al color, a su posición en la página, a los recursos gráficos y tipográficos que emplean y a los elementos que la componen.

Si comenzamos con la variable relativa al tamaño de la cabecera (ancho por alto con el total en $\mathrm{mm}$ ) la media se sitúa en torno a los $11.544 \mathrm{~mm}$, mientras que el tamaño medio de la mancha de los diarios analizados es de $86.050 \mathrm{~mm}$. Esto supone que el porcentaje que ocupa la cabecera en la portada con respecto a la mancha se situa en una media del $12,6 \%$.

En cuanto a la colocación de la cabecera hay que señalar que la mayor dificultad ha sido el establecer una regularización de las cabeceras en orden a su 
posicionamiento en la portada. Es cierto que la tendencia última en los diarios españoles es la de no mover el rótulo de forma habitual, tal y cómo se hacía en los años 60 a la mínima actualidad informativa, -como era el caso de Pueblo, $A B C$ y Marca, entre otros-. No obstante, sí podemos considerar que, aunque la gran mayoría de nuestros rotativos mantiene la cabecera centrada en la parte superior de la página, el hecho de que algunas de estas sean cortas y directas (Marca, As, $E l$ 9, ara, dxt y otros) obligan a un posicionamiento diferente (normalmente en la esquina superior izquierda) $\mathrm{y}$, por consiguiente, a un planteamiento de puesta en página distinto. Por ello, hemos establecido tres posiciones básicas -en lo que al eje vertical se refiere-:

1. Voladas: aparecen en la parte superior de la portada, sin nada por encima. Independientemente que aparezcan en negativo o positivo, con letra de serif o palo seco, alineadas al centro, a la izquierda o a la derecha. Este caso es el más abundante: 76 cabeceras (66\%).

2. Semivoladas: igual a las anteriores pero con la inclusión de informaciones del día por encima de ellas, bien en forma de rataplán, de destacados o de una única línea de cabeza que haga referencia a noticias del interior del diario. En este apartado está el 12,1\% de los casos (14 cabeceras).

En esquina, a un lado de la página, sin que llegue a cubrir todo el ancho, a modo de pastilla: son cabeceras que, por su corto nombre, aparecen en la ángulo superior izColocación vertical quierdo de las publicaciones, $\mathrm{y}$ permiten una estructura informativa más agresiva. Son el 21,7\% (25 cabeceras). Este recurso lo emplean casi todos los diarios deportivos (todos menos $A s$ ) y las publicaciones gratuitas (20 Minu-

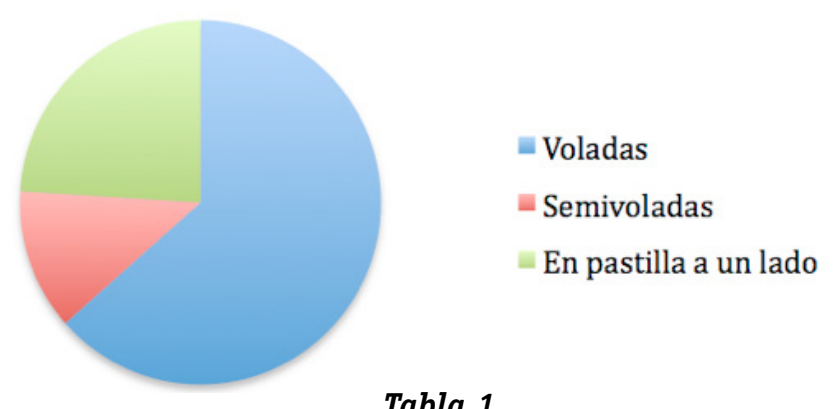
tos y Gente). 
En cuanto a la colocación de las cabeceras en el eje horizontal hay que señalar que el $34,7 \%$ se dispone a la izquierda (40), tan sólo dos van a la derecha -Regió7 y Diario de Gerona- $(1,7 \%)$ y la mayoría al centro, 73 , lo que supone un $63,4 \%$ de la muestra.

\section{Colocación horizontal}

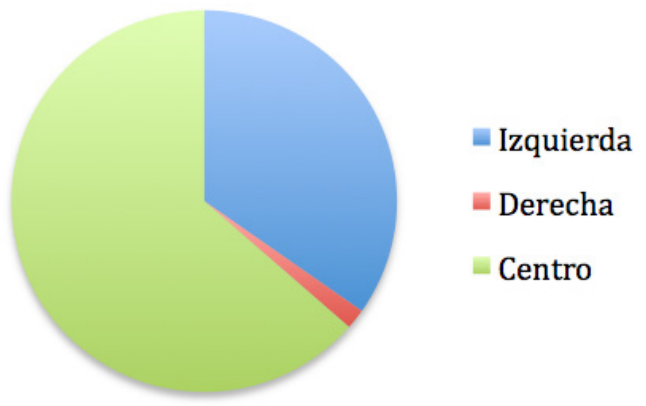

\section{Tabla 2}

En lo referente a la variable texto añadido al rótulo podemos decir que de los 115 diarios analizados 55 llevan una frase o lema añadido al rótulo (47,8\%). Y no lo llevan 60 diarios $(52,2 \%)$. En cuando a la frase literal que acompaña a éste hay que señalar que en la mayoría de los casos se indica el año de fundación o se hace referencia a la zona geográfica a la que pertenece.

En cuanto a la presencia de orejas en la cabecera hay que señalar que son mayoría -aunque apretada- las que no tienen, un 51,3\% (59 diarios). En el caso de las que sí tienen orejas, las de 56 diarios (un 48,6\%), hay que señalar que el contenido de las mismas es informativo (12); 13 tienen orejas publicitarias, tan sólo uno lleva orejas informativas y publicitarias al mismo tiempo y 30 cabeceras tienen orejas que incluyen datos registrales y/o de edición. En cuanto a su posición con respecto al rótulo, la mayoría de las veces se sitúan a la derecha (51 casos); tan sólo en dos casos se sitúan a la izquierda y en tres aparecen a ambos lados.

En lo referente a si aparece o no la edición web en la cabecera, hay que señalar que sí lo hace en el $66 \%$ de los casos (76) y no en el 34\% restante (39). Resulta interesante también constatar como dato curioso que tres cabeceras incorporan un código BIDI ( $E l$ Correo de Andalucía, Diario de Teruel y Bon Día (Lleida). 


\begin{tabular}{|c|c|}
\hline \multicolumn{2}{|r|}{ Frases literales o lemas } \\
\hline Superdeporte & El diario deportivo de la Comunitat Valenciana \\
\hline $\mathrm{dxt}$ & Primer diario deportivo de Galicia \\
\hline El 9 & Esportiu de Catalunya \\
\hline Mundo Deportivo & Fundado en 1905 \\
\hline El Economista & El líder económico en español \\
\hline 20 minutos & Fundado en 2000. El medio social \\
\hline Diario de Cádiz & Fundado en 1867 \\
\hline Sur & El periódico de Málaga desde 1937 \\
\hline Ideal & Diario regional de Andalucía \\
\hline Diario de Teruel & Fundado en 1936 \\
\hline Heraldo de Aragón & Diario independiente fundado en 1895 \\
\hline El Comercio & Diario Decano de la prensa asturiana. Fundado en 1878 \\
\hline La Nueva España & Diario Independiente de Asturias \\
\hline Diario de Ibiza & Dec ano de la prensa matutina balear. Fundado en 1893 \\
\hline Menorca & Diario insular \\
\hline Mediterráneo & El periódico de Castellón \\
\hline El Punt & Setmanario Independent, Valencià, Comarc al i Democràtic \\
\hline Las Provincias & El Diario de la Comunitat Valenciana. Desde 1866 \\
\hline Levante & El Mercantil Valenciano \\
\hline La Verdad & Periódico de la provincia de Alicante. Fundado en 1903 \\
\hline Diario de Avisos & $\begin{array}{l}\text { Decano de la prensa de Canarias } \\
\text { Fundado en Santa Cruz de la Palma en } 1890\end{array}$ \\
\hline La Provincia & Diario de Las Palmas \\
\hline El Diario Montañés & El Decano de la prensa cántabra. Desde 1902 \\
\hline El Adelantado de Segovia & Diario independiente fundado en 1901 por Don Rufino Cano de Rueda \\
\hline Diario de Burgos & Fundado el 1 de A bril de 1891 \\
\hline Diario de Ávila & Medallas de Oro de la Provincia y de las Cortes de Castilla y León \\
\hline Diario Palentino & Fundado en 1881 \\
\hline Diario de León & Decano de la prensa leonesa \\
\hline Diario de Soria & Decano de la prensa soriana \\
\hline Heraldo de Soria & Diario Independiente \\
\hline El Norte de Castilla & Diario Independiente fundado en 1854 \\
\hline Lanza & Diario de La Mancha \\
\hline La Tribuna de Albacete & Diario Independiente \\
\hline
\end{tabular}




\begin{tabular}{|l|l|}
\hline \multicolumn{2}{|c|}{ Frases literales o lemas } \\
\hline La Tribuna de Ciudad Real & Diario Independiente \\
\hline La Tribuna de Cuenca & Diario Independiente \\
\hline La Tribuna de Toledo & Diario Independiente \\
\hline Nueva Alcarria & El periódico de la provincia \\
\hline Diari de Terrassa & El Diari \\
\hline Diari de Girona & Fundat en 1889 \\
\hline La Vanguardia & Fundada en 1881 por Don Carlos y Don Bartolomé Godó \\
\hline Regió7 & El Diari de Catalunya Central \\
\hline Hoy & Diario de Extremadura \\
\hline Diario de Pontevedra & Fundado en 1889 \\
\hline El Progreso & Diario de Lugo desde 1908 \\
\hline Faro de Vigo & Diario Decano de la prensa nacional \\
\hline La Rioja & Diario de La Rioja des de 1889 \\
\hline El País & El periódico global en español \\
\hline La Razón & Diario independiente de información general. Nos gusta España \\
\hline La Gaceta & Diario de información y análisis de Intereconomía \\
\hline La Verdad & Fundado en 1903 \\
\hline Diario de Noticias & El periódico de todos los navarros. Nafar Guztion Egunkaria \\
\hline Deia & Gure Lurraren Deia \\
\hline Diario Vasco & Decano de la prensa guipuzcoana \\
\hline El Correo & El Correo español-El Pueblo Vasco desde 1910 \\
\hline Gara & Lectores con criterio \\
\hline & \\
\hline & Iabla 3 \\
\hline
\end{tabular}

Tabla 3

Las siguientes variables están relacionadas con los datos de edición y los registrales. Se da la circunstancia que todos los diarios de la muestra llevan incorporados en la cabecera datos de edición (fecha, precio, número de ejemplar, año, etc.) si bien, sólo 23 periódicos incorporan a la misma datos registrales (generalmente el nombre del director y el depósito legal).

Otra de las conclusiones que podemos obtener se deriva de las variables relacionadas con el empleo de recursos tipográficos no textuales. Podemos afirmar que un total de 75 cabeceras $(65,2 \%)$ sí emplean estos, en 74 casos han sido filetes y tan sólo en un caso bolos ( $E l M u n d o$ ). En lo que a los filetes se refiere, se contemplaron dos variables para analizar: el tipo de filete por dibujo (sólido, media caña 
o fantasía) y el tipo de filete por grosor (fino, semigrueso, luto o baqueta). En cuanto a la primera, domina de forma absoluta el tipo sólido con el $91,8 \%$ de los casos. Solo en cuatro casos se utilizaron medias cañas o cañas y en otros dos fantasías integradas por cinco filetes finos paralelos. En cuanto a la variable de tipos de filetes por grosor, los más utilizados son las baquetas, un 36\%, (27); le siguen los lutos, un 21,6\% (16), y después los finos con un 20,2\% (15) y los semigruesos también con 16 casos $(21,6 \%)$. Finalmente, también se ha podido constatar que las cabeceras de los diarios analizados no utilizan ningún otro recurso tipográfico no textual, salvo un filete punteado de color azul cerrando la cabecera del Diario de Teruel.

Para el análisis de las familias tipográficas empleadas en las cabececeras, hemos preferido hacer una abstracción lo más sencilla posible acudiendo a las categorías fijadas por Jean François Thibaudeau hacia 1924. Aunque entendemos que no es la más completa, sí pensamos que es clarificadora y suficiente para el empeño pretendido. De este modo, podemos señalar que la tipografía más empleada en las cabeceras de nuestros periódicos es de palo seco. De los 115 diarios analizados, el 46,9\% emplea letras de palo seco; el 40\% letras con remate, perteneciendo un $26,9 \%$ al grupo de las romanas antiguas, el $4,3 \%$ a las romanas modernas y el $8,6 \%$

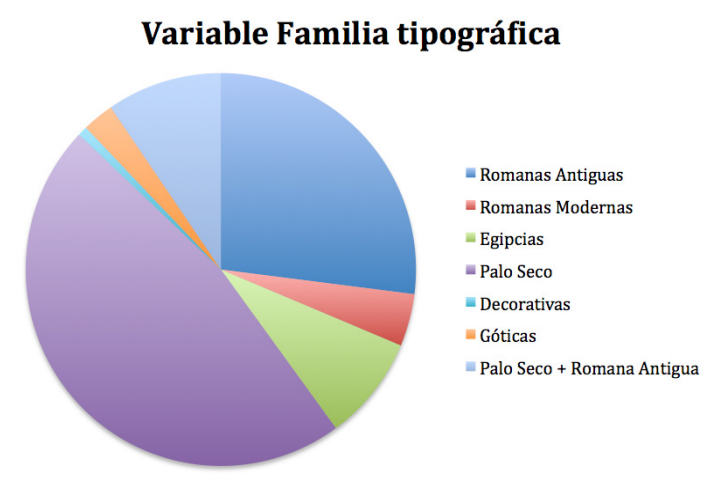

Tabla 4

DOI: ri14.v12i1.637 | ISSN: 1697-8293 | Año 2014 Volumen 12 Nº 1 | ICONO14 
a las egipcias. Hay que señalar también que un $9,5 \%$ de los diarios emplean en su rótulo tanto letras de palo seco como letras romanas antiguas. Añadir que son tres los diarios que emplean letras góticas (2,6\%) (Diario de León, La Voz de Galicia y El Norte de Castilla) y tan solo uno $(0,8 \%)$ caracteres decorativos (20 minutos).

En cuanto al cuerpo utilizado se ha atendido a la palabra de mayor impacto dentro del rótulo, y se ha medido en puntos Didot, obteniendo como resultado un tamaño medio de 120 puntos.

Desde el punto de vista del estilo la negrita domina de forma absoluta, el 92,1\% de las 115 cabeceras utilizan este estilo; sólo una va en cursiva $(0,8 \%)$, cuatro en negrita-cursiva $(3,4 \%)$ y otras cuatro en redonda (el 3,4\%).

\section{Variable Estilo}

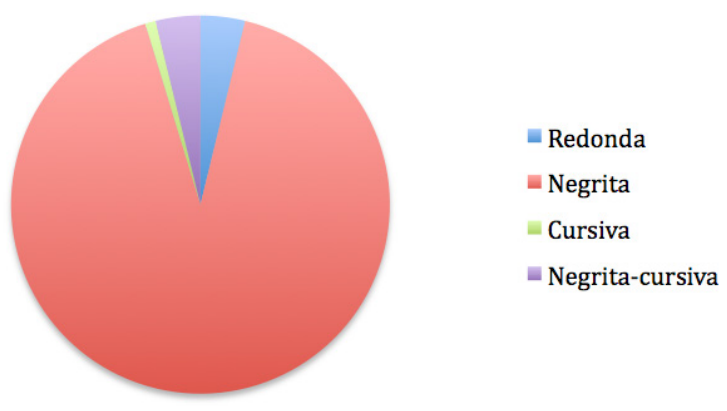

Tabla 5

El estilo ortotipográfico de estas categorías también ofrece datos a tener en cuenta. Tras nuestra investigación hemos podido constatar que el $52,1 \%$ de las cabeceras analizadas (un total de 60) emplean letras altas y bajas; el 41,7\% (48 rótulos) van compuestos en letras versales o de caja alta; tan solo cuatro en caja baja o minúscula, esto es, el 3,4\% (ara, as, berria y $d x t$ ) y tan solo el 2,6\% (tres cabeceras) en versalita (La Gaceta de Salamanca, Faro de Vigo y El Adelanto). 


\section{Variable Ortotipografía}

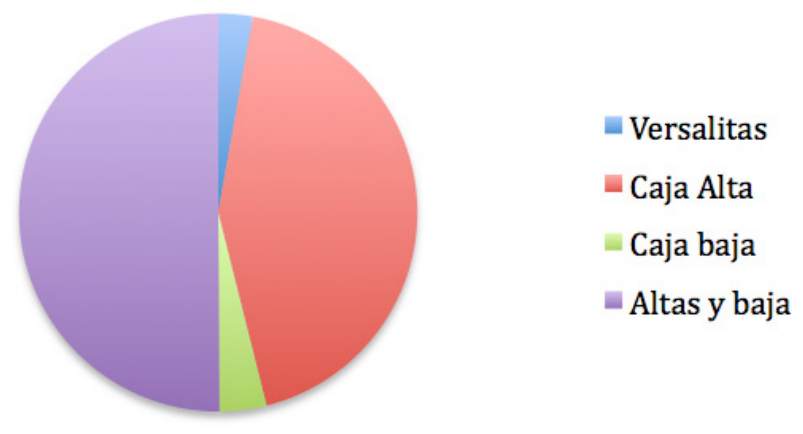

Tabla 6

Además, se ha podido constatar que 41 diarios emplean letras condensadas en el rótulo; hay seis que utilizan letras expandidas; tan sólo uno letras huecas (Sport) $\mathrm{y}$ otros seis letras sombreadas.

En lo referente a la variable relativa al uso de símbolos hay que añadir que la inclusión de escudos o emblemas en la cabecera está obsoleta pero, sin embargo, algunos periódicos mantienen esta costumbre. Es habitual encontrar este recurso en diarios regionales o locales, por ejemplo, todos los periódicos de los grupos PROMECAL y PROMECAM incorporan los escudos de la localidad donde se editan. También lo hace el diario Menorca. Sin embargo, entre las publicaciones nacionales sólo El Mundo (así como El Correo de Burgos, Diario de Valladolid y Diario de Soria, editados por Unidad Editorial) incorpora un elemento icónico -la esfera terrestre en color verde diseñada por Pepe Cruz Novillo-. También lo hace La Gaceta con el icono que representa un toro de color verde. Además, incorporan signos o símbolos en el logo los diarios regionales Málaga hoy, El Pueblo de Ceuta, La Región y El Día. En nuestro trabajo de campo incluímos cinco variables relacionadas con la presencia de símbolos y otros elementos icónicos en la cabecera. La primera hacía referencia al uso de símbolos en la misma. El dato es que tan solo quince de los diarios analizados (13\%) emplean símbolos en las cabeceras. Hemos decidido desestimar para el análisis la presencia de símbolos ocasionales que conmemoran aniversarios de los diarios. De esos 15 símbolos, y ya en lo referente a la variable tamaño del mismo, 6 son grandes y 9 pequeños. En cuanto a la situación del símbolo en la 
cabecera 9 se sitúan a la izquierda, 2 a la derecha y 4 al centro. En lo referente al empleo del color, uno va calado en blanco, siete van en blanco y negro y los otros siete en color.

Desde el punto de vista del color, hay que señalar que 20 diarios $(17,3 \%)$ emplean el mismo color en el rótulo (en 11 casos es el negro; en 4, azul; en 4, rojo y 1 en blanco). En lo que al color principal del rótulo se refiere, los números arrojan un resultado contundente: el negro es el color dominante en más de la mitad de los casos, 50,4\%. Los otros dos colores dominantes más empleados son el azul $(27,8 \%)$ y el rojo $(16,5 \%)$, a los que añadir los residuales verde $(2,6 \%)$ y el blanco con el mismo porcentaje. Conviene tener en cuenta dos cosas: una, que nos referimos siempre al color dominante en la cabecera; dos, que haya cabeceras que manejan dos o más tonos.

\section{Color principal del rótulo}

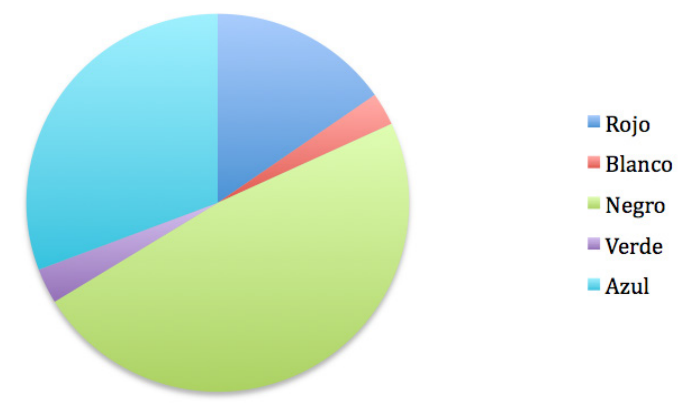

Tabla 7

En cuanto al segundo color del rótulo hay que señalar que 20 cabeceras no emplean ningún color secundario ya que todo el rótulo es del mismo color $(17,3 \%)$. Entre los 95 casos restantes, los que sí emplean un segundo color, domina de forma aplastante el blanco, con un 28,6\%, al que sigue el rojo con 14 casos $(12,1 \%)$, el azul con $12(10,4 \%)$ y el negro con $11(9,5 \%)$. Por detrás se sitúa el verde, con 10 casos $(8,6 \%)$, amarillo y naranja con $4(3,4 \%)$ y $3(2,6 \%)$ casos respectivamente. Finalmente, podemos destacar la presencia testimonial del gris y el púrpura con dos casos cada uno $(1,7 \%)$ y el albero con un solo caso $(0,8 \%)$. 


\section{Color secundario del rótulo}

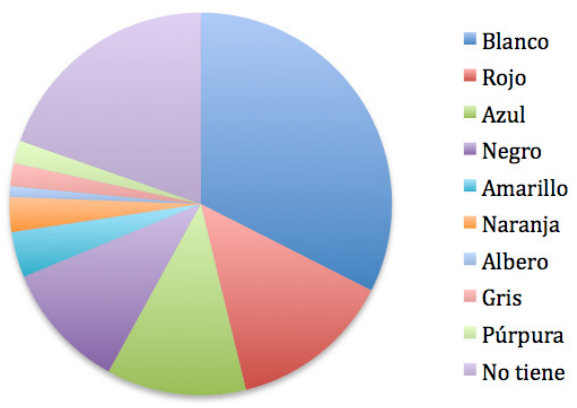

Tabla 8

En cuanto a los colores empleados como fondos del rótulo el $62,5 \%$ no lleva ninguno, es decir, el fondo es blanco; el 17,3\% va en azul, siendo éste el color más utilizado en las cabeceras que van en negativo; el 10,4\% presenta un fondo rojo; el 3,4\% verde y tan solo el 0,8\% negro; y el mismo porcentaje en amarillo -solo un diario-. Destaca el caso de $A B C$ que siempre lleva la cabecera calada sobre la imagen de portada.

\section{Color principal de fondo}

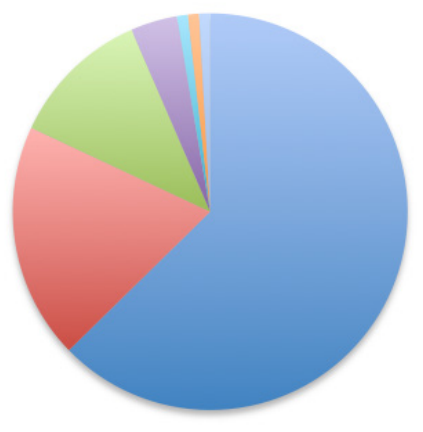

$$
\begin{aligned}
& =\text { No hay color } \\
& =\text { Azul } \\
& =\text { Rojo } \\
& =\text { Verde } \\
& =\text { Negro } \\
& =\text { Amarillo } \\
& =\text { Calado }
\end{aligned}
$$

Tabla 9

En lo que a la variable color se refiere, se ha obtenido también como resultado que 20 diarios utilizan un sólo color en la cabecera (17,3\%); el 41,7\%, utiliza dos colores; el 32,1\%, tres colores y el 8,6\% de los casos presenta el número máximo de colores, que son cuatro. 


\section{Número de colores presentes en la cabecera}

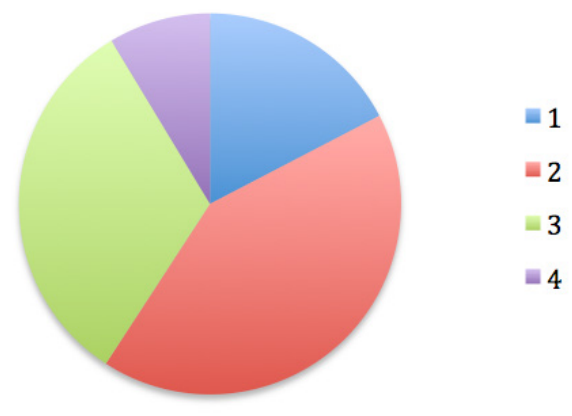

Tabla 10

Finalmente, en lo que a la estampación del rótulo se refiere, existe una dicotomía clásica en las cabeceras que no podíamos pasar por alto: su impresión en positivo o en negativo (contratipo). Hay un claro predominio de la mancha negro sobre blanco con el $70,4 \%$ de los casos (81 cabeceras). El negativo aparece, por tanto, en el $26,9 \%$. Es curioso consignar que hay tres diarios $(2,6 \%)$ que combinan estos dos efectos: Diario de Teruel, Majorca Daily Bulletin y el deportivo El 9.

\section{Estampación del rótulo}

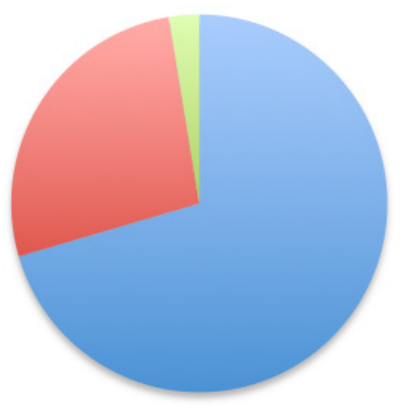

- Positivo

Negativo

Ambas

Tabla 11 


\subsection{Variables cognitivas, intencionales e interpretativas}

Tal y como se recoge en el apartado metodológico, la variable $n^{0} 51$ trata de determinar los modelos de diarios en su relación diseño/contenido que, según los autores consultados, establece patrones de puesta en página asociados a contenidos concretos. Entendemos que el aspecto gráfico y tipográfico de la cabecera puede ser uno de los elementos que refleje esta relación.

El análisis de la muestra, conforme a las categorías establecidas por Casasús (1981), arroja los siguientes resultados: de los 115 periódicos, 8 son diarios deportivos, 3 de información económica y 2 gratuitos. El resto, esto es, 102 diarios, son de información general, dentro de los cuales consideramos que 18 respondenal modelo informativo-interpretativo y 84 al modelo híbrido informativo-popular. No hemos encontrado ningún modelo de opinión, ni sensacionalista puro, tampoco híbrido en la variante informativo-opinión.

Por su parte, los periódicos deportivos se encuadran todos dentro del modelo popular-sensacionalista, mientras que los económicos obedecen al modelo informativo-interpretativo. Sin embargo, los diarios gratuitos participan de las característica de los diarios híbridos informativos-populares.

En lo que a la variable $n^{0} 52$ se refiere hemos comprobado que todos los diarios deportivos ofrecen una portada del tipo póster $\mathrm{y}$, al contrario, los económicos presentan una portada de sumario. Decir también que los gratuitos tienen este mismo tipo de portada. En cuanto a los diarios de información general hay que resaltar el hecho de que en su gran mayoría todas son de escaparate. Únicamente dos ( $A B C$ y La Razón) ofrecen a sus lectores portadas de tipo póster.

De la observación del comportamiento de estas variables, podemos señalarla evolución de la prensa española, en los últimos años, hacia una disminución de los modelos de prensa, y se hace más homogénea al encasillarse, en su mayoría, en el modelo híbrido informativo-popular hacia el que los grupos de prensa se dirigen: un modelo que procura ordenar el diario con base en criterios informativos evidentes pero que, para ello, utiliza recursos gráficos que se podrían considerar 'poco 
serios' (grandes masas de color, tipografías en caja alta a tamaños desmesuarados, diversos centros de interés visual en la página, ordenamientos con criterios de interés humano antes que informativos...).

Y por otro lado, ya no existen diarios puros de opinión en el conjunto de la prensa española y tampoco podemos considerar ningún rotativo que se encuadre en el modelo híbrido informativo-opinión.

\section{Discusión}

Del cruce de las variables morfológicas e interpretativas recogidas en la ficha metodológica la conclusión que a nuestro juicio se revela como más significativa es el hecho de que existe una relación evidente entre el modelo de diario atendiendo a la relación diseño/contenido y la tipografía empleada en la cabecera. Podemos afirmar que la mayor parte de los diarios informativos interpretativos $(72,2 \%)$ emplean tipografías con serif, con un peso medio y un aspecto sobrio, impresas en negro sobre blanco. Dentro del mismo modelo, el 22,3\% corresponde a familias de palo seco y tan sólo un 5,5\% a letras góticas.

En lo que al modelo híbrido informativo-popular se refiere las conclusiones se invierten, la categoría tipográfica dominante en estas cabeceras es la de palo seco, con un 48,6\%. Le sigue la categoría con serif, un 39,2\%; en un 9,4\% las cabeceras presentan juntas ambas categorías. Por último, las góticas aparecen en un 2,8\% de los casos.

Esta tendencia de asimilar tipografía empleada en la cabecera a modelo de diario se acentúa en la prensa deportiva y económica. En la primera, que responde al modelo popular-sensacionalista, con portadas tipo póster, seis de las ocho cabeceras (75\%) pertenecen al grupo de palo seco, tan solo dos llevan remate. Si bien es cierto que el peso de ambos rótulos en Marca (egipcia) y As (romana antigua) es de tal fuerza que iguala, o incluso supera, la mancha de una tipografía de palo seco.

En los diarios económicos, que responden de manera clara al modelo informativointerpretativo, y presentan una portada de escaparate, no hay duda, el 100\% de las cabeceras utilizan tipografías con serif. 
A modo de colofón apuntamos también que las cabeceras en la prensa diaria española, por lo general, se rigen por los parámetros que marcan los modelos más en boga de cada momento. A día de hoy, la mayoría de los periódicos en España responden a las exigencias impuestas por los grupos editoriales a los que pertenecen. La concentración de los medios de comunicación en las grandes empresas multimedia se produce por una doble vía. En primer lugar, existen diarios creados directamente por los grupos editoriales $\mathrm{y}$, por otra parte, la supervivencia de numerosas publicaciones de histórica relevancia pasa por la compra o absorción del periódico por parte de los grupos mediáticos. Son estos últimos los que conservan algunas de las características de su antigua cabecera, aunque siempre respetando los rasgos fundamentales impuestos por el grupo. La concentración informativa está ocasionando una pérdida de identidad en muchos de los diarios de larga tradición.

El grupo Joly, líder del sector en Andalucía, y Vocento han sido recientemente los casos más evidentes. Respecto a las cabeceras de Vocento, hay que diferenciar entre $A B C$, de tirada nacional, y el resto de regionales. $A B C$ mantiene su propio diseño y no tiene pautas comunes con el resto de publicaciones del grupo. Por el contrario, los regionales de Vocento vivieron un antes y un después del rediseño de 2009. Ese año se rediseñaron todos de manera conjunta, manteniendo unos elementos comunes al grupo, cabeceras en positivo, voladas a la izquierda, en negrita y con un friso por debajo, pero marcando la diferencia, ya que se mantenían las tipografías originales de cada publicación, para imprimirles el valor de tradición y no perder la familiaridad con el lector. Al contrario que Vocento, el grupo Joly prefirió conservar las tipografías originales de cada publicación, para imprimirles el valor de tradición y no perder la familiaridad con el lector.

El panorama actual de las cabeceras de los diarios españoles responde a un mismo modelo que cada grupo mediático sigue en mayor o menor medida. Por ejemplo, las cabeceras de los diarios de los grupos PROMECAL y PROMECAM son idénticas, si bien en el caso de los diarios de Castilla y León cambia el color del luto que cierra la cabecera.

DOI: ri14.v12i1.637 | ISSN: 1697-8293 | Año 2014 Volumen 12 Nº 1 | ICONO14 
Por lo general, la cabecera de las publicaciones diarias ocupa todo el ancho de la portada. Suele aparecer centrada y abarca, en altura, la octava parte del tamaño de la mancha. Ésta es una muestra de la importancia del rótulo sobre los demás elementos de la publicación. El valor de la cabecera como elemento icónico, símbolo y muestra de la identidad del diario, justifica su colocación dentro de la página como el eje principal del que surgen los demás componentes de la portada.

La cabecera de los diarios pretende ser una llamada de atención para el potencial consumidor. Si el rótulo le transmite la idea de un producto informativo que responde a sus intereses y tras su adquisición confirma que la imagen de la portada se corresponde con los contenidos, el consumidor se familiarizará con la publicación.

La conclusión general que resulta tras analizar las tendencias actuales en el diseño de cabeceras para publicaciones diarias impresas es que el rótulo se ha convertido en el símbolo de cualquier diario, la imagen detrás de la que está la empresa periodística en cuestión. Y así lo demuestra el hecho de que en las versiones digitales de los diarios se emplee la misma cabecera que en su versión impresa aunque con ligeras modificaciones. Como dice López del Ramo (2012: 15) “el grado de similitud entre la cabecera impresa y la digital es un indicativo simbólico-visual del nivel de autonomía entre el ciberdiario y su diario matriz. Los resultados obtenidos reflejan que en este momento existen ya muchos elementos diferenciadores entre ambos medios, aunque no puede hablarse de una independencia total, sobre todo por el mantenimiento del rótulo clásico del impreso en la mayoría de los periódicos digitales".

El diseño de este elemento icónico busca transmitir los valores que cada publicación concreta considera suyas, unos valores que se corresponden con los del lector potencial. Por ello, las connotaciones subjetivas de la tipografía empleada y de los colores que aparecen en la cabecera son el principal medio de transporte para esas ideas que se quieren transmitir. 


\section{Referencias}

Arnold, E. (1956). Funtional newspaper design. Nueva York: Harper and Row. Arnold, E. (1965). Tipografia y diagramado para periódicos. Nueva York:

Mergenthaler Linotype Company.

Arnold, E. (1986). Diseño total de un periódico. Méjico: Edamex.

Canga Larequi, J. (1994). El diseño periodístico en prensa diaria. Madrid:Bosh

Casa Editorial Comunicación.

Casasús, J. M. (1979). Ideología y análisis de medios de comunicación. Madrid:

DOPESA.

Gäde, R. (2002). Diseño de Periódicos. Sistema y Método. Barcelona: Gustavo Gili. García, M. R. (1984). Diseño y remodelación de periódicos. Navarra: Eunsa. González Díez, L. \& Pérez Cuadrado, P. (2001). Principios Básicos sobre Diseño

Periodístico. Madrid: Universitas.

González Díez, L. \& Pérez Cuadrado, P. (2006). Cabeceras, cabezotes, cabezales, rótulos, logotipos y manchetas. Madrid: ADCV.

González Solas, J. (2002). Identidad visual corporativa. Madrid: Síntesis. Lallana García, F. (2000). Tipografia y diseño. Madrid: Síntesis.

López del Ramo, J. (2012). “Análisis comparativo de las cabeceras de los diarios digitales españoles respecto a los impreso". Anales de Documentación. vol.15, n 2. Madrid. ISSN: 1697-7904. http://dx.doi.org/10.6018/ analesdoc.15.2.150831.

Mainar, R. (1906). El arte del periodista. Madrid: Gallach.

Martínez de Sousa, J. (1981). Diccionario general de Periodismo. Madrid:

Paraninfo.

Martínez de Sousa, J. (1991). Diccionario de información, comunicación y periodismo. Madrid: Paraninfo.

Martín Aguado, J. A. (1987). Lectura estética y técnica de un diario. Madrid: Alhambra Universidad.

Martín García, M. (2004). “Construcción de marcas y diseño".Visual,nº 106.

Disponible en http://www.visual.gi/index2005.htm (consultado el 13/06/2013).

Martínez-Fresneda Osorio, H. (2007). La comunicación a través del diseño periodístico. Madrid: Editorial Fragua.

DOI: ri14.v12i1.637 | ISSN: 1697-8293 | Año 2014 Volumen 12 Nº 1 | ICONO14 
62 | Laura González Díez y Pedro Pérez Cuadrado

Pablos Coello, J. M. de (2003). Tipografia para periodistas. Madrid: Editorial Universitas.

Rehe, R. (1990). Tipografía y diseño de periódicos. Alemania: IFRA.

Santesmases Mestre, M. (1999). Marketing. Conceptos y Estrategias. Madrid:

Pirámide.

Sutton, A. (1963). Concepción y confección de un periódico. Madrid: Rialp.

Vílchez de Arribas, F. (2011). Historia Gráfica de la prensa diaria española (17561976). Barcelona: RBA.

VV. AA. (1991). Diccionario Anaya de la Lengua. Madrid: Anaya.

V. AA. (2001). Diccionario de la Real Academia. Tomo I. Madrid: Espasa Calpe.

VV.AA. (2004). España en portada. Análisis de las primeras páginas de los diarios nacionales y su influencia en la sociedad. Madrid: Fragua.

ICONO14 | Año 2014 Volumen 12 № 1 | ISSN: 1697-8293 | DOI: ri14.v12i1.637 